Article

\title{
Effects of Environmental Factors on Concrete Carbonation Depth and Compressive Strength
}

\author{
Ying Chen ${ }^{1,2}$, Peng Liu ${ }^{1,2, *}$ and Zhiwu Yu ${ }^{1,2}$ \\ 1 School of Civil Engineering, Central South University, 22 Shaoshan Road, Changsha 410075, China; \\ cheny83@csu.edu.cn (Y.C.); zhwyu0512@163.com (Z.Y.) \\ 2 National Engineering Laboratory for High Speed Railway Construction, 22 Shaoshan Road, \\ Changsha 410075, China \\ * Correspondence: 2015038@csu.edu.cn
}

Received: 19 September 2018; Accepted: 31 October 2018; Published: 2 November 2018

\begin{abstract}
The influence of temperature, $\mathrm{CO}_{2}$ concentration and relative humidity on the carbonation depth and compressive strength of concrete was investigated. Meanwhile, phase composition, types of hydration products and microstructure characteristics of samples before and after the carbonation were analyzed by XRD and ESEM. Research results demonstrate that temperature, $\mathrm{CO}_{2}$ concentration and relative humidity influence the carbonation depth and compressive strength of concrete significantly. There is a linear relationship between temperature and carbonation depth, as well as the compressive strength of concrete. $\mathrm{CO}_{2}$ concentration and relative humidity present a power function and a polynomial function with carbonation depth of concrete, respectively. The concrete carbonation depth increases with the increase of relative humidity and reaches the maximum value when the relative humidity is $70 \%$. Significant differences of phase composition, hydration products and microstructure are observed before and after the carbonation. Carbonization products of samples are different with changes of temperatures $\left(10^{\circ} \mathrm{C}, 20^{\circ} \mathrm{C}\right.$ and $\left.30^{\circ} \mathrm{C}\right)$. The result of crystal structure analysis indicates that the carbonation products are mainly polyhedral spherical vaterite and aragonite.
\end{abstract}

Keywords: concrete; carbonation depth; temperature; relative humidity; $\mathrm{CO}_{2}$ concentration; compressive strength

\section{Introduction}

Factors like environmental or exposure conditions are found to be governing the service life of reinforced concrete structures significantly. One of the major processes influencing the condition of steel bars is carbonation of concrete surrounding steel bars in reinforced concrete structures. Hence, considerable research efforts on the carbonation of concrete in the laboratory and field are carried out around the world [1]. Concrete carbonation is a complex physical and chemical reaction between hydration products of cements and $\mathrm{CO}_{2}$. Concrete carbonation easily induces a decrease of the system $\mathrm{pH}$, decomposition of hydration products, depassivation of deactivated film of reinforcing bar and cracking of the concrete cover. Therefore, concrete carbonation is a serious problem for the durability of concrete structures [2,3].

Many achievements on concrete carbonation have been reported in the world [4-6]. Lee et al. [7] explored the influence of carbonation on chloride penetration in concrete structures, and the test results indicated that the chloride penetration was more pronounced when the carbonation process was combined with the chloride ingress. Castel et al. [8] investigated the effect of loading on carbonation penetration in reinforced concrete elements, and an accuracy model was proposed to predict the increase of the carbonation depth of the concrete in relation to the tensile stress in rebar. Concrete 
carbonation is mainly influenced by concrete properties and external environmental factors. All factors interact and restrict mutually and are highly uncertain $[9,10]$. Existing studies mainly focused on material composition, mixing proportion and carbonation depth of concrete [11-14]. For example, Zhao et al. [15] studied the effect of the material factors on the carbonation properties of the concrete and proposed the carbonation coefficient values of the concrete mixtures with various material factors. Atis [16] discussed the influence of fly ash, superplasticizer and water to cement ratio on the carbonation of concrete. Lye et al. [17] investigated the influences of crack, freeze-thaw cycling and carbonation on the mechanical properties and durability of reinforced concrete.

Although the analysis of the influences of environmental factors on concrete carbonation has been conducted [18-20], existing research conclusions mainly focused on the influences of temperature and $\mathrm{CO}_{2}$ concentration on the products, microstructure and depth of concrete carbonation. Ronaldo et al. [11] proposed that microclimatic factors such as temperature and local humidity, sunshine, wind, wetting and drying cycles might have been responsible for the behavior of carbonation in concrete. Cui et al. [21] investigated the relationship between the depth of concrete carbonation and $\mathrm{CO}_{2}$ concentration. Andreas et al. [22] discussed the effect of $\mathrm{CO}_{2}$ concentration and ambient relative humidity on accelerated and natural carbonation of 18 concrete mixtures produced with nine different cement types, and the results indicated that the water-to-cement ratio and cement-specific effect affected the relative carbonation resistance between the concrete mixtures.

Those above research shortages determine the poor accuracy of the theoretical model of concrete carbonation and the great gap between prediction results and measured results. This makes prediction of the endurance lifetime of actual engineering more apt for the concrete carbonation empirical model of concrete. It is urgent to study the influences of environmental factors on concrete carbonation performances for the sake of better evaluation on concrete endurance, disclosure of the carbonation mechanism and prediction of the service life of the concrete engineering structure.

In this study, the influence of temperature and $\mathrm{CO}_{2}$ concentration and relative humidity on concrete carbonation was investigated. Carbonation depth and compressive strength of concrete with different strength grades under different environmental conditions were tested. Moreover, phase composition, as well as types and microstructure of hydration products before and after carbonation were analyzed by X-ray diffraction (XRD) and the environment scanning electron microscope (ESEM).

\section{Experimental Procedure}

\subsection{Raw Materials}

The $\mathrm{P}_{+} \mathrm{O} 42.5$ Portland cement was provided by China Building Materials Academy. The fly ash produced by Hunan Xiangtan Power Plant was low calcium fly ash (i.e., F class). The physical properties of cement and fly ash are listed in Table 1, and the chemical compositions of fly ash are listed in Table 2. River sands and continuous grading limestone gravels with a grain size of $5-20 \mathrm{~mm}$ were collected. Tap water, which met the JGJ63-2006 Water Standards for Concrete, was applied in the stirring process. The polycarboxylic acid series of a high-efficiency superplasticizer, which contained $30 \%$ of solid, was from Huangteng Co. Ltd. (Changsha, Hunan, China). Three strength grades of concrete mixing proportions were prepared (Table 3), which was the concrete mix for a lab building's floor, wall and column.

Table 1. Physical properties of cement and fly ash.

\begin{tabular}{|c|c|c|c|c|c|c|c|}
\hline Items & $\begin{array}{l}\text { Fineness } \\
(74-\mu \mathrm{m} \\
\text { mesh) }(\%)\end{array}$ & $\begin{array}{l}\text { Density } \\
\left(\mathrm{g} / \mathrm{cm}^{3}\right)\end{array}$ & $\begin{array}{c}\text { Specific } \\
\text { Surface Area } \\
\left(\mathrm{m}^{2} / \mathrm{kg}\right)\end{array}$ & $\begin{array}{c}\text { Water } \\
\text { Requirement of } \\
\text { Normal } \\
\text { Consistency (\%) }\end{array}$ & $\begin{array}{l}\text { Initial Setting } \\
\text { Time (min) }\end{array}$ & $\begin{array}{l}\text { Final Setting } \\
\text { Time (min) }\end{array}$ & $\begin{array}{l}\text { Compressive } \\
\text { Strength (28 d) } \\
\text { (MPa) }\end{array}$ \\
\hline Fly ash & 1.5 & 2.83 & 322 & - & - & - & - \\
\hline
\end{tabular}


Table 2. Chemical compositions of fly ash (\%).

\begin{tabular}{cccccccccc}
\hline $\mathrm{CaO}$ & $\mathrm{SiO}_{2}$ & $\mathrm{Al}_{2} \mathrm{O}_{3}$ & $\mathrm{Fe}_{2} \mathrm{O}_{3}$ & $\mathrm{MgO}$ & $\mathrm{Na}_{2} \mathbf{O}$ & $\mathrm{K}_{\mathbf{2}} \mathrm{O}$ & $\mathrm{SO}_{3}$ & $\mathbf{P}_{2} \mathrm{O}_{3}$ & Loss \\
\hline 2.57 & 54.0 & 27.7 & 6.11 & 1.23 & 0.37 & 1.50 & 0.14 & - & 2.56 \\
\hline
\end{tabular}

Table 3. Mix of concrete $\left(\mathrm{kg} / \mathrm{m}^{3}\right)$.

\begin{tabular}{ccccccc}
\hline Items & Cement & Fly Ash & $\begin{array}{c}\text { Fine } \\
\text { Aggregate }\end{array}$ & $\begin{array}{c}\text { Coarse } \\
\text { Aggregate }\end{array}$ & Water & $\begin{array}{c}\text { Water } \\
\text { Reducer }\end{array}$ \\
\hline C20 & 195 & $128(39.6 \%)$ & 785 & 1045 & 178 & 1.8 \\
C30 & 270 & $125(31.6 \%)$ & 780 & 1050 & 172 & 1.9 \\
C40 & 350 & $122(25.8 \%)$ & 710 & 1052 & 162 & 2.25 \\
\hline
\end{tabular}

Note: The values in bracket are the ratio of fly ash to total amount of cementitious materials.

\subsection{Experimental Process}

Concrete specimens $(100 \mathrm{~mm} \times 100 \mathrm{~mm} \times 300 \mathrm{~mm}$ and $100 \mathrm{~mm} \times 100 \mathrm{~mm} \times 100 \mathrm{~mm})$ were cast according to GB/T 50082-2009 Standards on the Test Method of Ordinary Concrete Long-term Performance and Endurance. Specimens were demolded after $24 \mathrm{~h}$ of casting, and 120 specimens were cast for each concrete grade. Then, they were cured at a temperature of $(20 \pm 1){ }^{\circ} \mathrm{C}$ and a relative humidity of $(95 \pm 5) \%$ for $28 \mathrm{~d}$. Subsequently, the specimens were dried for $48 \mathrm{~h}$ at $60{ }^{\circ} \mathrm{C}$. After drying, the specimens were placed in the environmental simulation test chamber for a week to ensure the same temperature and humidity between the concrete interior and external environment. In order to obtain the carbonation result of concrete in a short time, the high $\mathrm{CO}_{2}$ concentration was adopted. Therefore, the corresponding concrete carbonation of this study belonged to the accelerated carbonation test method, and the results were applicable to characterize the change of accelerated carbonation test. Carbonation testing conditions of concrete were acquired by the environmental simulation test system. After the concrete carbonation test reached the preset carbonation age (28 d), the compressive strength and carbonation depth of specimens were tested subsequently. Carbonation depth of concrete was tested by $1 \%$ phenolphthalein reagent, which was prepared by $95 \%$ ethyl alcohol. Ten points on the cross-section of specimen were measured, and the corresponding average value was set as the carbonation depth with a precision of $0.1 \mathrm{~mm}$. The cement paste with a water to cement ratio of 0.258 was prepared to investigate the hydrations before and after carbonation by XRD analysis. The carbonation conditions of cement paste were the same as the corresponding concrete specimens. Meanwhile, the concrete sample was prepared to carry out ESEM analysis. The mechanical properties of concrete were tested according to the GB/T50081-2002 Standards on the Test Method of Ordinary Concrete Mechanical Properties under the loading rate of $5 \mathrm{kN} / \mathrm{s}$. The average value of three samples was set as the compressive strength of each group.

\subsection{Test Instruments and Devices}

Test instruments mainly included a Quanta-200 environment scanning electron microscope (ESEM) made by FEI Company (Hillsboro, OR, USA), a WAW-DP Universal tester made by Shanghai Sansi Co. Ltd. (Shanghai, China) and the environmental simulation test system made by Wuhan Jinyatai Instrument Co. Ltd. (Wuhan, China). Moreover, BD-86 X-ray diffraction (XRD) produced by Rigaku Company (Akishima, Japan) was used to investigate the hydration products. The corresponding scanning step was $0.02^{\circ}$, and the scanning range was from $5^{\circ}-60^{\circ}$ with a tube voltage and rated power of $60 \mathrm{kV}$ and $4 \mathrm{~kW}$, respectively. 


\section{Results and Discussions}

\subsection{Effects of Temperature on Carbonation Depth and Compressive Strength of Concrete}

Generally, concrete carbonation is a complicated physical and chemical reaction. Temperature can influence the chemical reaction significantly. In this paper, the influences of temperature $\left(10{ }^{\circ} \mathrm{C}\right.$, $20^{\circ} \mathrm{C}$ and $30{ }^{\circ} \mathrm{C}$ ) on concrete carbonation were analyzed by the changes of carbonation depth and compressive strength of concrete, which had been carbonized for $28 \mathrm{~d}$ under $70 \%$ relative humidity and a $20 \% \mathrm{CO}_{2}$ concentration. The variation curves of carbonation depth and compressive strength of concrete with temperature are shown in Figures 1 and 2, respectively.

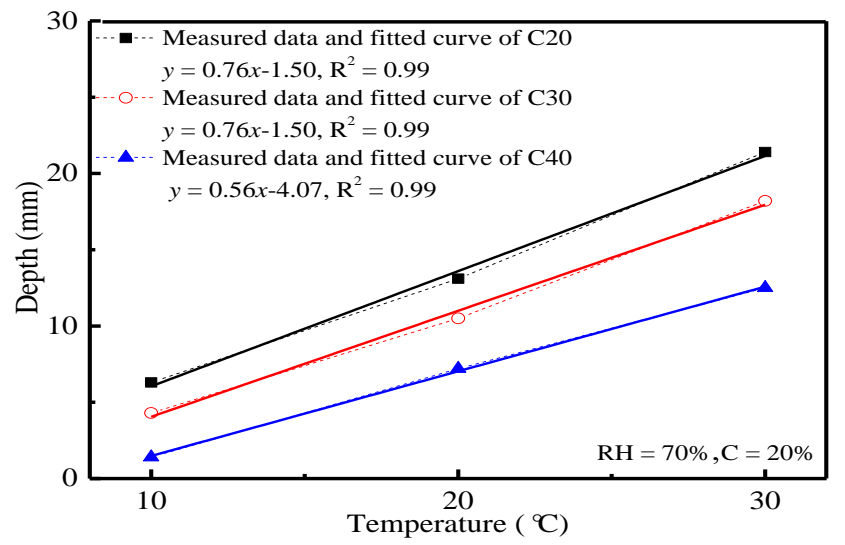

Figure 1. Relation curve between the carbonation depth of concrete and temperature.

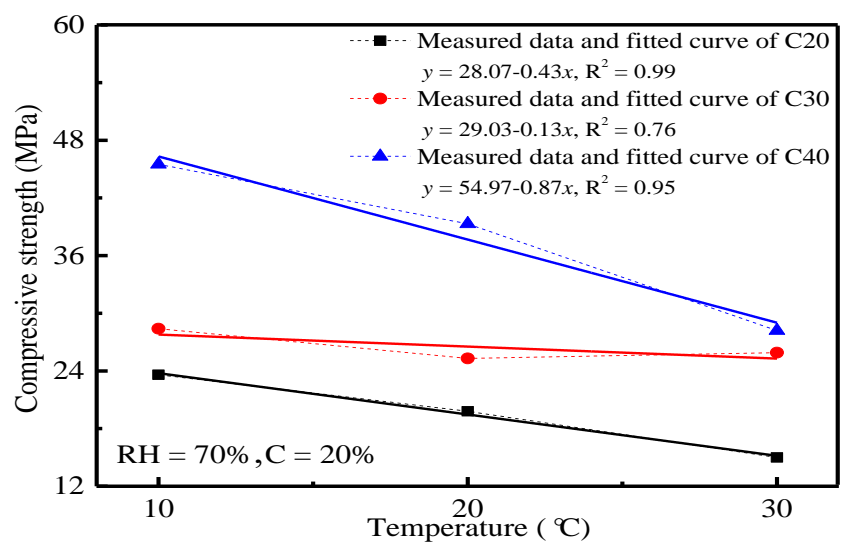

Figure 2. Relation curve between the compressive strength of concrete and temperature.

It can be seen from Figure 1 that there is a good linear relationship between the carbonation depth of concrete and temperature. Given the same environmental conditions, the carbonation depth of concrete decreased with the increase of the strength grade of concrete. This was because the $\mathrm{CO}_{2}$ concentration and carbonation reaction rate in concrete were higher as a response to the high transmission coefficient of $\mathrm{CO}_{2}$ and the chemical reaction coefficient under high temperature. Although the carbonation reaction rate of concrete presented a nonlinear relationship with temperature, $\mathrm{CO}_{2}$ concentration in concrete took the dominant role, and the whole concrete carbonation was controlled by the transmission of $\mathrm{CO}_{2}$. Generally speaking, the transmission coefficient of $\mathrm{CO}_{2}$ was closely related to the temperature. Hence, there was a basically linear relationship between the carbonation depth of concrete and temperature. With the increase of concrete strength grade, the microstructure of concrete was manifested by higher density, lower porosity, higher complexity of pore structural characteristics and sinuosity, as well as smaller openness of pores. Combined with Table 2, it can also be seen that the carbonation depth decreased with the decrease of fly ash content. This may be due to more hydration products generated from cement $[23,24]$, so the carbonation resistance 
was good. As a result, the transmission coefficient of $\mathrm{CO}_{2}$ in concrete decreased. If the concrete carbonation process was controlled by $\mathrm{CO}_{2}$ transmission in concrete, the carbonation depth of concrete was negatively correlated with concrete strength grade. At the same time, products from the reaction between hydration products and $\mathrm{CO}_{2}$ in the concrete surface filled in some pores, which further increased the surface density of concrete and decreased the $\mathrm{CO}_{2}$ transmission coefficient in concrete. Hence, the carbonation reaction of concrete declined.

In Figure 2, the compressive strength of concrete decreased with the increase of temperature. A strong linear relationship between them was observed. This could be explained as follows. Concrete carbonation may induce the reaction of $\mathrm{CO}_{2}$ with hydration products, such as calcium hydroxide (i.e., $\mathrm{CH}$ ), calcium silicate hydrate (i.e., $\mathrm{CSH}$ ), ettringite (i.e., $\mathrm{AFt}$ ) and calcium aluminate hydrate (i.e., $\mathrm{CAH}$ ) in concretes, through which gelling hydration products were decomposed and carbonates and calcium silicates without gelling properties were produced. This induced deterioration of the concrete microstructure changes of the hydration products and destroys the chemical balance in the system. Hence, the compressive strength of concrete declined as the carbonation continued. The $\mathrm{CO}_{2}$ transmission coefficient and chemical reaction coefficient in concrete increased with the increase of carbonation temperature, which resulted in a higher concrete carbonation degree. Comparing with Figures 1 and 2, the compressive strength of concrete was closely related to the carbonation depth. The higher the carbonation depth is, the sharper the reduction of the compressive strength of concrete will be. This proved indirectly that concrete carbonation may cause changes of the internal microstructure, the decomposition of hydration products and the deterioration of the macroscopic performances of concrete.

\subsection{Effects of Relative Humidity on the Carbonation Depth and Compressive Strength of Concrete}

The influencing law of relative humidity on carbonation depth and compressive strength of concrete was analyzed, as shown in Figures 3 and 4.

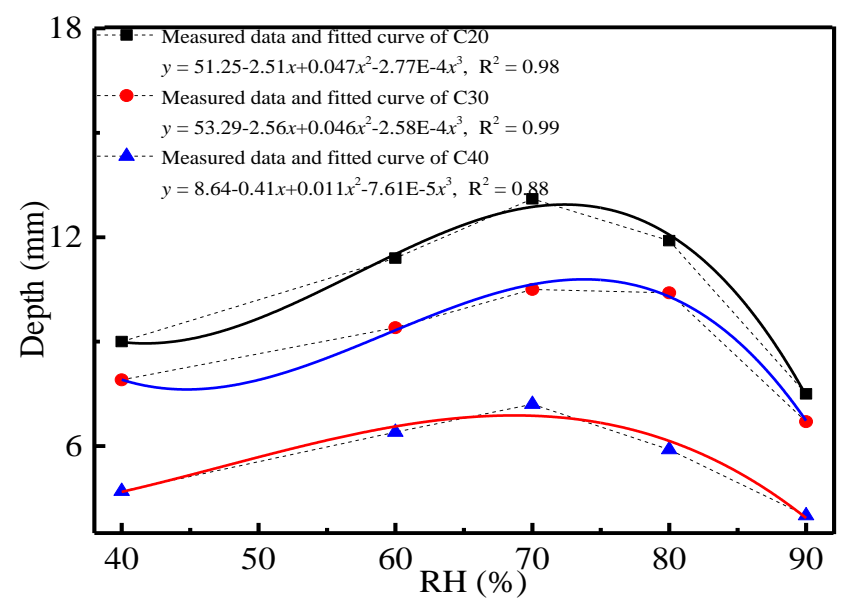

Figure 3. Relationship curve between relative humidity and the carbonation depth of concrete. 


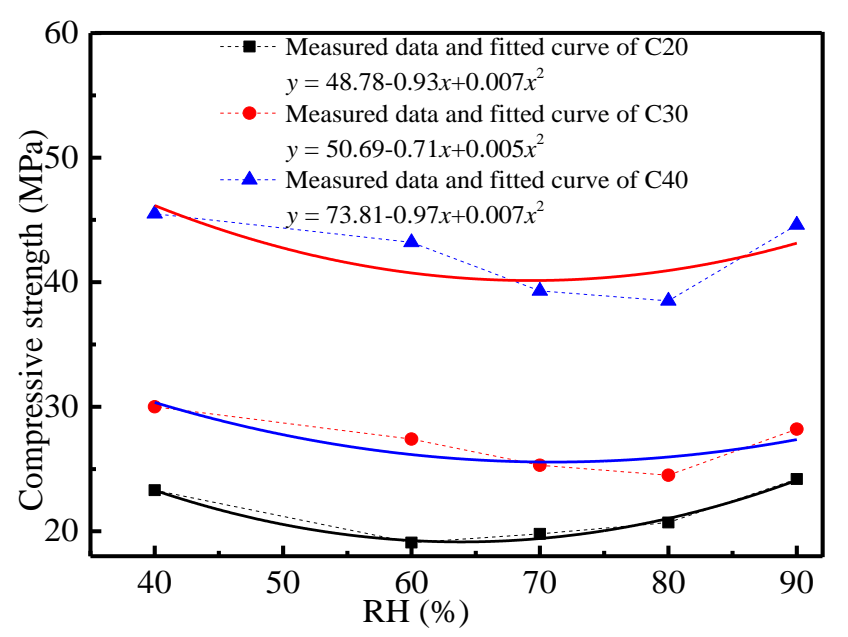

Figure 4. Relation curve between the compressive strength of concrete and relative humidity.

In Figure 3, relative humidity influenced the carbonation depth of concrete significantly. Specifically, the carbonation depth of concrete increased with the increase of relative humidity and reached the peak when the relative humidity was $70 \%$. The carbonation depth of concrete decreased gradually with the continuous growth of relative humidity. It showed a polynomial function between relative humidity and carbonation depth. This reflected that the concrete carbonation rate and degree were the highest when the relative humidity was $70 \%$. Abundant pores in concrete can be filled in by water vapor and generate liquid water under a certain relative humidity. The water vapor can decrease pore connection in a certain radius of pores. The $\mathrm{CO}_{2}$ transmission coefficient in liquid water in concrete pores was very small, which decreased the $\mathrm{CO}_{2}$ transmission quantity and rate in concrete accordingly. Therefore, the concrete carbonation depth decreased under relatively high relative humidity $(>70 \%)$. When the relative humidity was low, water vapor in concrete pores may cover up pore walls and form a liquid film. Different hydration products of cement (mainly $\mathrm{CH}$ ) were dissolved in the film, and the corresponding oversaturated solution was formed. $\mathrm{CO}_{2}$ was transmitted into concrete pores and dissolved in the film to react with $\mathrm{CH}$ to generate calcium carbonate. The continuous carbonation consumed abundant ions. This induced decomposition of hydration products in the system and caused further changes of the chemical equilibrium state in the system. If the relative humidity was low, the film area and thickness on the pore wall in concrete were too small to support the carbonation of the system. Therefore, the corresponding concrete carbonation was slow. With the increase of relative humidity, the water content in concrete pores increased, which was conducive to concrete carbonation. Macroscopically, this was manifested by the increase of the carbonation depth of concrete with the increase of relative humidity. The carbonation depth of concrete began to decrease after the relative humidity exceeded a fixed value (about $70 \%$ ). This deduction could be verified by the changes of the compressive strength of concrete with relative humidity (Figure 4).

Figure 4 shows that the compressive strength of concrete changed with the increase of relative humidity. In a certain range of relative humidity $(60-80 \%)$, a reduction of compressive strength of concrete reached the extreme value. With the increase of relative humidity, the reduction amplitude of the compressive strength of concrete decreased to some extent. This was because under a certain relative humidity, pores within a certain diameter range in concrete can be saturated by water vapor, which may be transformed into liquid water in pores, which filled some pores in concrete and thereby decreased $\mathrm{CO}_{2}$ transmission in concrete. Therefore, carbonation in concrete was dominated by $\mathrm{CO}_{2}$ transmission under excessive relative humidity. The corresponding carbonation depth of concrete was relatively low, and the reduction of compressive strength under high humidity was relatively small. Nevertheless, the liquid water content in concrete pores was positively related to relative humidity in a certain range $(<70 \%)$. It could offer places for dissolution and reaction of hydration products (e.g., $\mathrm{CH}$ ), which increased carbonation depth and rate accordingly. As the carbonation continued, 
microstructure and hydration products of the system changed, which were manifested by a reduction of the compressive strength of concrete macroscopically.

\subsection{Effects of $\mathrm{CO}_{2}$ on the Carbonation Depth and Compressive Strength of Concrete}

The effects of $\mathrm{CO}_{2}$ concentration on the carbonation depth and compressive strength of concrete were also investigated. The variation curves of carbonation depth and compressive strength of concrete at $28 \mathrm{~d}$ and the $\mathrm{CO}_{2}$ concentration are shown in Figures 5 and 6.

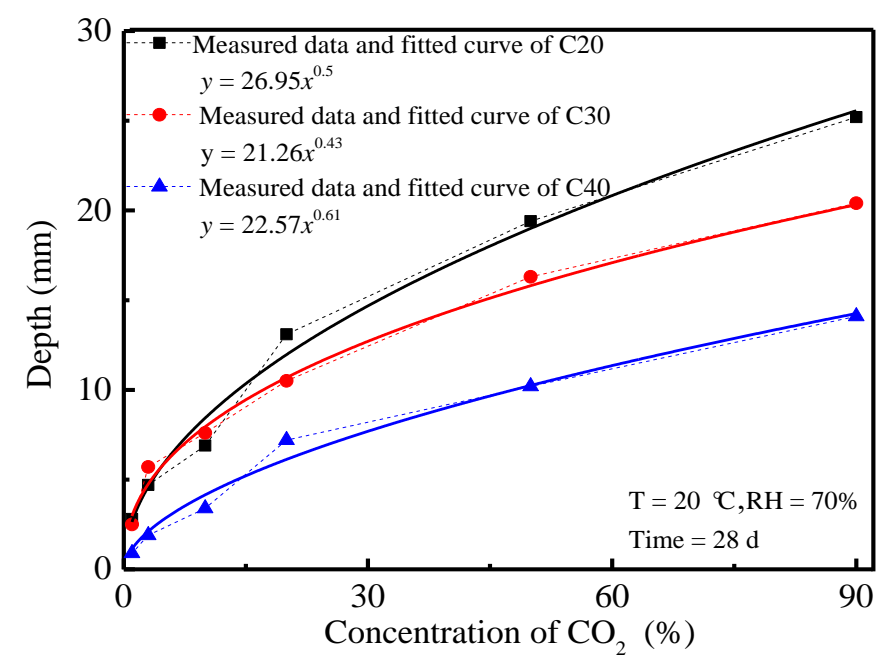

Figure 5. Relation curves between the carbonation depth of concrete and $\mathrm{CO}_{2}$ concentration.

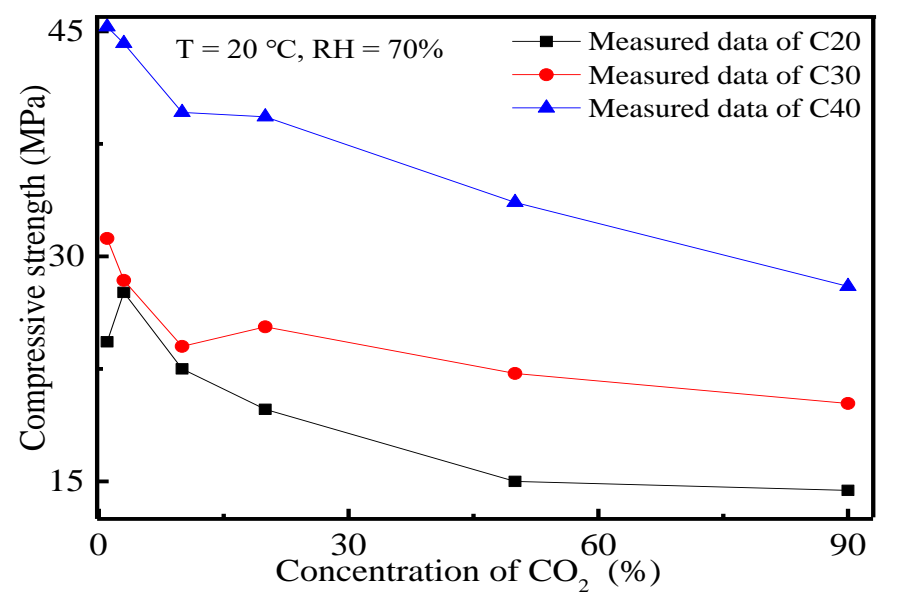

Figure 6. Relation curves between the compressive strength of concrete and $\mathrm{CO}_{2}$ concentration.

In Figure 5, carbonation depth of concrete under the same carbonation conditions increased with the increase of $\mathrm{CO}_{2}$ concentration. A power function between them was observed. Under the same $\mathrm{CO}_{2}$ concentration, carbonation depth of concrete was negatively correlated with the strength grade of concrete. Given the higher $\mathrm{CO}_{2}$ concentration, the inner-outside concentration gradient was larger, and more $\mathrm{CO}_{2}$ could diffuse into the concrete and react with the hydration products in concrete. The growth rate of carbonation depth decreased as $\mathrm{CO}_{2}$ concentration increased. This was because there was a low $\mathrm{CO}_{2}$ concentration in the early carbonation of concrete and the $\mathrm{CO}_{2}$ quantity transmitted into concrete was consumed by a fast reaction. As the $\mathrm{CO}_{2}$ concentration increased, the $\mathrm{CO}_{2}$ quantity transmitted into the concrete was higher than the $\mathrm{CO}_{2}$ consumption by concrete carbonation. Concrete carbonation was controlled by chemical reaction rather than the $\mathrm{CO}_{2}$ transmission. As a result, the change rate of the concrete carbonation depth curve decreased gradually with the increase of $\mathrm{CO}_{2}$ concentration. A high strength grade of concrete implied a higher density, lower porosity and more closed pores in concrete, 
as well as the lower $\mathrm{CO}_{2}$ transmission coefficient in concrete. Hence, $\mathrm{CO}_{2}$ quantity transmitted into concrete decreased accordingly. Moreover, a higher strength grade of concrete demanded greater cement consumption and more hydration products in the hydration reactions, which helped the system to absorb more $\mathrm{CO}_{2}$. Therefore, the carbonation depth of concrete was negatively related to the strength grade of concrete. This could be verified by the relation curves between the compressive strength of concrete and $\mathrm{CO}_{2}$ concentration. Changes of the compressive strength of concrete after $28 \mathrm{~d}$ of carbonation under different $\mathrm{CO}_{2}$ concentrations are shown in Figure 6. Temperature and relative humidity were set to $20^{\circ} \mathrm{C}$ and $70 \%$, respectively.

It can be seen from Figure 6 that the compressive strength of concrete decreased with the increase of $\mathrm{CO}_{2}$ concentration. Under the same test conditions, the influences of the carbonation effect on concrete strength intensified in response to the decreasing strength grade of concrete. Since concrete carbonation was the reaction between gelling hydration products (e.g., $\mathrm{CH}, \mathrm{CSH}, \mathrm{CAH}$ and $\mathrm{AFt}$ ) and $\mathrm{CO}_{2}$, hydration products were decomposed and decreased. The system microstructure was loosened and deteriorated accordingly, thus decreasing the compressive strength of concrete. With the increase of $\mathrm{CO}_{2}$ concentration, the $\mathrm{CO}_{2}$ concentration gradient inside and outside of the concrete surface, as well as the $\mathrm{CO}_{2}$ quantity transmitted into the concrete increased. Therefore, there was more $\mathrm{CO}_{2}$ participating in the reaction and decomposition of the abundant hydration products that caused the microstructure failure of concrete. Macroscopically, this was manifested by a reduction of the compressive strength of concrete. For $\mathrm{C} 20$ concrete, a low $\mathrm{CO}_{2}$ concentration may increase the concrete strength. This might be caused by $\mathrm{CO}_{2}$ reacting with the hydration products in the concrete surface. The reaction products were generated and filled in some part of the pores, which enhanced the density of the concrete microstructure. The positive effect of carbonation in a short period was caused by the dominant role of the concrete microstructure.

\subsection{XRD and ESEM Analysis before and after the Concrete Carbonation}

The types of hydration products and the phase composition of specimens before and after the carbonation were analyzed to disclose the carbonation mechanism of concrete and its performance changes. The XRD spectra of the phase composition before and after the carbonation are shown in Figure 7.

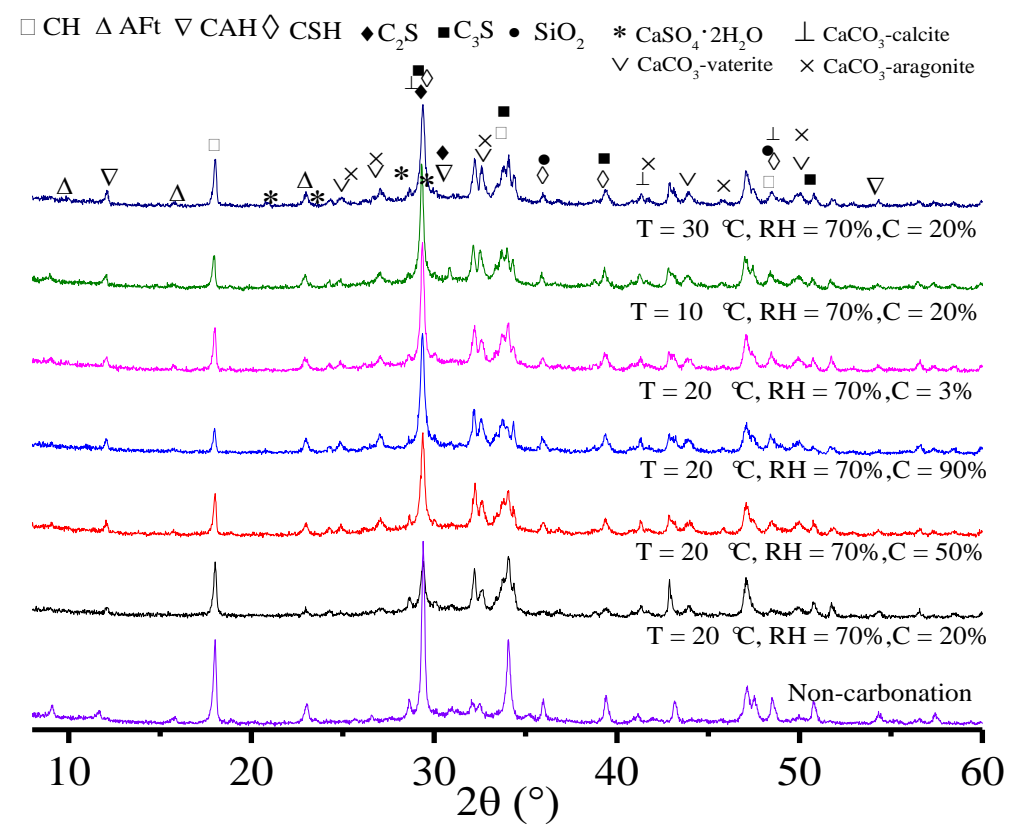

Figure 7. XRD spectra of the phase composition before and after carbonation. 
It can be seen from Figure 7 that there was a significant difference in the XRD spectra before and after the carbonation, which manifested as the intensity, disappearance and generation of the diffraction peak. The diffraction peak of hydration products of non-carbonation specimens demonstrated that $\mathrm{CH}$, $\mathrm{AFt}, \mathrm{CSH}$ and $\mathrm{CAH}$ were major hydration products. However, the diffraction peaks of different crystal styles of calcium carbonate (i.e., calcite, vaterite and aragonite) were observed when the specimens were carbonized, which implied that the carbonation product was calcium carbonate. There were significant differences in the phase composition and products of specimens when the temperature and $\mathrm{CO}_{2}$ concentration were different. These were mainly manifested by the attenuation (e.g., $\mathrm{CH}, \mathrm{CSH}$ and $\mathrm{CAH}$ ) and disappearance (e.g., $\mathrm{AFt}$ ) of the diffraction peaks of some cement gelling hydration products, as well as the appearance and strengthening of the diffraction peaks of carbonation products (e.g., $\mathrm{CaCO}_{3}$ ). When the temperature and relative humidity were fixed, the diffraction peak intensity of $\mathrm{CaCO}_{3}$ was positively related to $\mathrm{CO}_{2}$ concentration. The $\mathrm{CaCO}_{3}$ content in carbonized samples increased. This was because more and more $\mathrm{CO}_{2}$ may be transmitted into samples and react with hydration products in the system under the high $\mathrm{CO}_{2}$ concentration. Figure 7 also reflected that under the same $\mathrm{CO}_{2}$ concentration and relative humidity, the phase composition and diffraction peaks of hydration products changed more significantly with the increase of temperature. This was caused by the faster decomposition of the carbonation products and hydration products of the system under the higher temperature.

The microstructure and product morphology before and after the carbonation were studied to investigate the influences of temperature on concrete carbonation. The ESEM spectra of specimens before and after the carbonation under different temperature are shown in Figure 8.

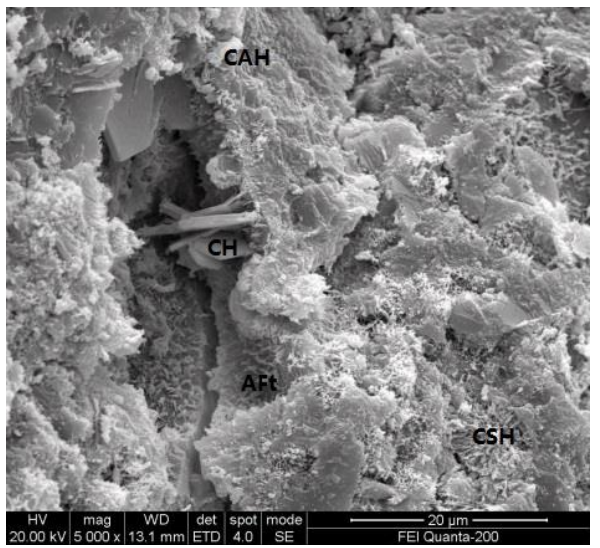

(a) Non-carbonation

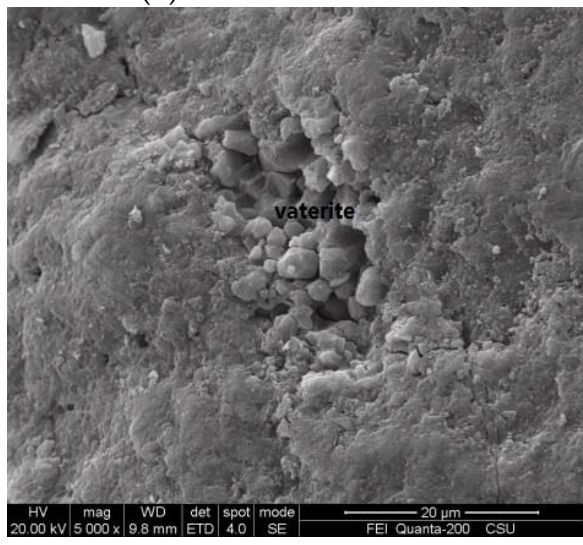

(c) Carbonation at $20^{\circ} \mathrm{C}$

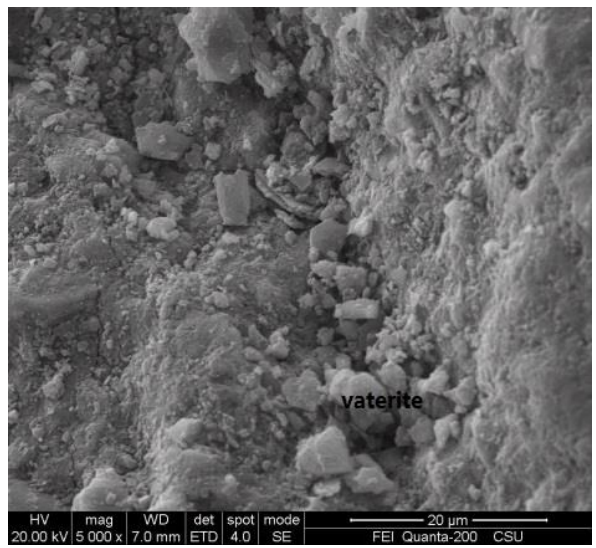

(b) Carbonation at $10^{\circ} \mathrm{C}$

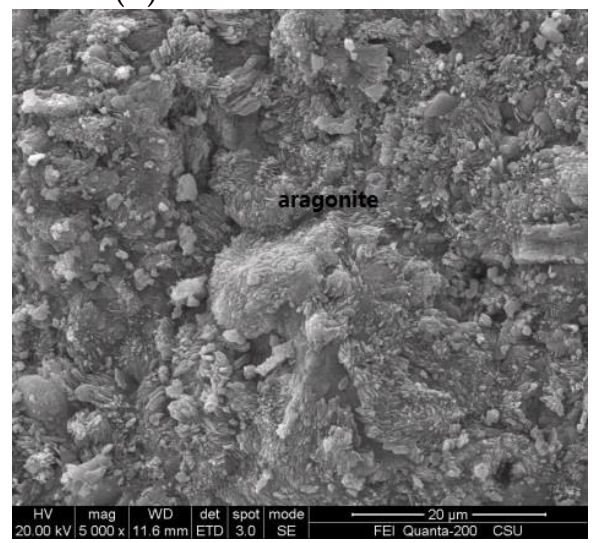

(d) Carbonation at $30^{\circ} \mathrm{C}$

Figure 8. ESEM spectra of carbonation specimens under different temperatures.

In the ESEM spectra of non-carbonation samples, the hydration products were mainly hexagonal plate-like $\mathrm{CH}$, rod-like AFt, flocculent $\mathrm{CSH}$ and $\mathrm{CAH}$ (Figure 8a). Nevertheless, there were few gelling 
hydration products in the microstructure of carbonized specimens and particulate $\mathrm{CaCO}_{3}$ in the pores. The carbonation products of specimens under different temperatures were also different to some extent. Specifically, polyhedral vaterites could be observed in the ESEM spectra of carbonized samples under $10^{\circ} \mathrm{C}$ and $20^{\circ} \mathrm{C}$ (Figure $8 \mathrm{~b}, \mathrm{c}$ ). Under $30^{\circ} \mathrm{C}$, the microstructure and morphology of the hydration products of carbonized samples were significantly different from those under $10^{\circ} \mathrm{C}$ and $20{ }^{\circ} \mathrm{C}$ (Figure 8d). Hexagonal plate-like $\mathrm{CH}$, arborization $\mathrm{CSH}$, flocculent $\mathrm{CAH}$ and rod-like AFt disappeared, and abundant aragonites were generated, which implied the decomposition and destruction of the original cementitious hydration of cement. These phenomena were the consequence of thermodynamic equilibrium states under different temperatures. The chemical reaction between $\mathrm{CO}_{2}$ and hydration products in the system took place under different temperatures, which produced $\mathrm{CaCO}_{3}$ crystals of different forms.

\section{Conclusions}

1 Temperature, $\mathrm{CO}_{2}$ concentration and relative humidity influence the carbonation depth and compressive strength of concrete significantly. Temperature has a linear relationship with the carbonation depth and compressive strength of concrete. $\mathrm{CO}_{2}$ concentration and relative humidity present power and polynomial functions with the carbonation depth of concrete, respectively.

2 The carbonation depth of concrete is positively correlated with temperature and $\mathrm{CO}_{2}$ concentration, but the compressive strength of concrete is negatively correlated with the strength grade of concrete. The carbonation depth of concrete increases with the increase of the relative humidity and reaches the peak when the relative humidity is $70 \%$. This is because the $\mathrm{CO}_{2}$ transmission coefficient and chemical reaction coefficient may increase with temperature. Besides, the increase of the $\mathrm{CO}_{2}$ concentration may bring the increase of the concentration gradient and the $\mathrm{CO}_{2}$ concentration in concrete, as well as the intensified carbonation. Concrete density is positively related to the strength grade of concrete. The $\mathrm{CO}_{2}$ transmission coefficient in concrete is low, which may decrease the carbonation depth of concrete.

3 The phase composition, hydration products and microstructure of concrete change significantly before and after the carbonation. Such changes are mainly manifested by the disappearance and attenuation of the diffraction peak of some hydration products. XRD and ESEM spectral analysis reveal that hexagonal plate-like $\mathrm{CH}$, rod-like $\mathrm{AFt}$, flocculent $\mathrm{CSH}$ and $\mathrm{CAH}$ are major hydration products before the carbonation, but particulate $\mathrm{CaCO}_{3}$ takes the dominant role in hydration product composition after the carbonation. Temperature affects the crystal form of carbonation products. Polyhedral spherical vaterites are major carbonation products under $10{ }^{\circ} \mathrm{C}$ and $20^{\circ} \mathrm{C}$, whereas aragonites are the major carbonation products under $30^{\circ} \mathrm{C}$.

Author Contributions: Y.C. conceived and designed the experiments; Z.Y. and P.L. analyzed the data and wrote the paper.

Funding: This research was funded by the Natural Science Foundation of China, grant numbers 51778632, U1434204 and 51408614, the China Postdoctoral Science Foundation, Grant Numbers 2016M600675 and 2017T100647, the Guangdong Provincial Key Laboratory of Durability for Marine Civil Engineering, grant numbers GDDCE14-03, 15-08, 17-02, 18-03, the Basic Research on Science and technology program of Shenzhen, grant number JCYJ20170818143541342, and the Natural Science Foundation of Hunan Province of China, grant number 2017JJ3385.

Conflicts of Interest: The authors declare no conflict of interest.

\section{References}

1. Verma, S.K.; Bhadauria, S.S.; Akhtar, S. Determination of carbonation depth through in-situ testing of concrete structures. Rev. Romama Mater. 2015, 45, 226-231.

2. Saetta, A.V.; Vitaliani, R.V. Experimental investigation and numerical modeling of carbonation process in reinforced concrete structures Part II: Practical applications. Cem. Concr. Res. 2005, 35, 958-967. 
3. Cheng, Y.C.; Zhang, Y.W.; Jiao, Y.B.; Yang, J.S. Quantitative analysis of concrete property under effects of crack, freeze-thaw and carbonation. Constr. Build. Mater. 2016, 129, 106-115. [CrossRef]

4. Garcia, S.T.; Yepes, V.; Alcala, J. Life cycle greenhouse gas emissions of blended cement concrete including carbonation and durability. Int. J. Life Cycle Assess. 2014, 19, 3-12. [CrossRef]

5. Alexander, M.G.; Mackechnie, J.R.; Yam, W. Carbonation of concrete bridge structures in three South African localities. Cem. Concr. Comp. 2007, 29, 750-759. [CrossRef]

6. Singh, N.; Singh, S.P. Reviewing the carbonation resistance of concrete. J. Mater. Eng. Struct. 2016, 3, 35-37.

7. Lee, M.K.; Jung, S.H.; Oh, B.H. Effects of carbonation on chloride penetration in concrete. ACI Mater. J. 2014, $111,458-459$.

8. Castel, A.; Francois, R.; Arliguie, G. Effect of loading on carbonation penetration in reinforced concrete elements. Cem. Concr. Res. 1999, 29, 561-565. [CrossRef]

9. Northwood, D.O.; Roy, S.K.; Beng, P.K. The carbonation of concrete structures in the tropical environment of singapore and a comparison with published data for temperate climates. Mag. Concr. Res. 1996, 48, 293-300.

10. Talukdar, S.; Banthia, N.; Grace, J.R.; Cohen, S. Carbonation in concrete infrastructure in the context of global climate change: Part 2-Canadian urban simulations. Cem. Concr. Comp. 2012, 34, 931-935. [CrossRef]

11. Medeiros, R.A.; Lima, M.G.; Yazigi, R.; Medeiros, M.H.F. Carbonation depth in 57 years old concrete structures. Steel Compos. Struct. 2015, 19, 953-966. [CrossRef]

12. Talukdar, S.; Banthia, N.; Grace, J.R. Carbonation in concrete infrastructure in the context of global climate change-Part 1: Experimental results and model development. Cem. Concr. Comp. 2012, 34, 924-930. [CrossRef]

13. Kumazaki, K. Large time behavior of a solution of carbon dioxide transport model in concrete carbonation process. J. Differ. Equ. 2014, 257, 2136-2158. [CrossRef]

14. Chang, C.F.; Chen, J.W. The experimental investigation of concrete carbonation depth. Cem. Concr. Res. 2006, 36, 1760-1767. [CrossRef]

15. Zhao, H.; Sun, W.; Wu, X.M.; Gao, B. The effect of the material factors on the concrete resistance against carbonation. KSCE J. Civ. Eng. 2018, 22, 1265-1274. [CrossRef]

16. Atis, C.D. Accelerated carbonation and testing of concrete made with fly ash. Constr. Build. Mater. 2003, 17, 147-152. [CrossRef]

17. Lye, C.Q.; Dhir, R.K.; Ghataora, G.S. Carbonation resistance of fly ash concrete. Mag. Concr. Res. 2015, 67, 1150-1178. [CrossRef]

18. Zhang, D.; Shao, Y. Effect of early carbonation curing on chloride penetration and weathering carbonation in concrete. Constr. Build. Mater. 2016, 123, 516-526. [CrossRef]

19. Banthia, N.; Cohen, S.; Talukdar, S.; Grace, J. Climate change-induced carbonation of concrete infrastructure. Constr. Mater. 2014, 167, 140-150.

20. Steffens, A.; Dinkler, D.; Ahrens, H. Modeling carbonation for corrosion risk prediction of concrete structures. Cem. Concr. Res. 2002, 32, 935-941. [CrossRef]

21. Cui, H.Z.; Tang, W.C.; Liu, W.; Dong, Z.J.; Xing, F. Experimental study on effects of $\mathrm{CO}_{2}$ concentrations on concrete carbonation and diffusion mechanisms. Constr. Build. Mater. 2015, 93, 522-527. [CrossRef]

22. Leemann, A.; Moro, F. Carbonation of concrete: the role of $\mathrm{CO}_{2}$ concentration, relative humidity and $\mathrm{CO}_{2}$ buffer capacity. Mater. Struct. 2017, 50, 30-43. [CrossRef]

23. Golewski, G.L. Generalized fracture toughness and compressive strength of sustainable concrete including low calcium fly ash. Materials 2017, 10, 1393. [CrossRef] [PubMed]

24. Golewski, G.L. Green concrete composite incorporating fly ash with high strength and fracture toughness. J. Clean. Prod. 2018, 172, 218-226. [CrossRef]

(C) 2018 by the authors. Licensee MDPI, Basel, Switzerland. This article is an open access article distributed under the terms and conditions of the Creative Commons Attribution (CC BY) license (http://creativecommons.org/licenses/by/4.0/). 